\title{
Applying the Global Disturbance Index for Detecting Vegetation Changes in Lao Tropical Forests
}

\author{
Chittana Phompila ${ }^{1,2}$, Megan Lewis ${ }^{2}$, Kenneth Clarke², Bertram Ostendorf ${ }^{2}$ \\ ${ }^{1}$ Faculty of Forestry, The National University of Laos, Vientiane, Lao People's Democratic Republic \\ ${ }^{2}$ School of Biological Sciences, The University of Adelaide, Adelaide, Australia \\ Email: chittana.phompila@adelaide.edu.au, megan.lewis@adelaide.edu.au, Kenneth.clarke@adelaide.edu.au, \\ bertram.ostendorf@adelaide.edu.au
}

Received 2 March 2015; accepted 16 March 2015; published 23 March 2015

Copyright (C) 2015 by authors and Scientific Research Publishing Inc.

This work is licensed under the Creative Commons Attribution International License (CC BY).

http://creativecommons.org/licenses/by/4.0/

(c) (i) Open Access

\begin{abstract}
Land cover change is a major challenge for many developing countries. Spatiotemporal information on this change is essential for monitoring global terrestrial ecosystem carbon, climate and biosphere exchange, and land use management. A combination of LST and the EVI indices in the global disturbance index (DI) has been proven to be useful for detecting and monitoring of changes in land covers at continental scales. However, this model has not been adequately applied or assessed in tropical regions. We aimed to demonstrate and evaluate the DI algorithm used to detect spatial change in land covers in Lao tropical forests. We used the land surface temperature and enhanced vegetation index of the Moderate Resolution Imaging Spectroradiometer time-series products from 2006-2012. We used two dates Google Earth ${ }^{\text {TM }}$ images in 2006 and 2012 as ground truth data for accuracy assessment of the model. This research demonstrated that the DI was capable of detecting vegetation changes during seven-year periods with high overall accuracy; however, it showed low accuracy in detecting vegetation decrease.
\end{abstract}

\section{Keywords}

Tropical Vegetation Change, Disturbance Index, Land Surface Temperature (LST), Enhanced Vegetation Index (EVI), Lao PDR

\section{Introduction}

Global measures of land cover change are important for global terrestrial ecosystem carbon schemes, climate

How to cite this paper: Phompila, C., Lewis, M., Clarke, K. and Ostendorf, B. (2015) Applying the Global Disturbance Index for Detecting Vegetation Changes in Lao Tropical Forests. Advances in Remote Sensing, 4, 73-82.

http://dx.doi.org/10.4236/ars.2015.41007 
and biosphere exchange modeling [1]-[3], and for improving our understanding of human and environmental interactions [4]-[6] with vegetation condition and structure [7]. Biodiversity loss due to land cover change is one of the core management challenges at both global and regional scale [8] [9]. Adequate spatiotemporal information is critical for monitoring this change [10]-[12]. However, obtaining accurate spatiotemporal information of the timing and location of land cover change is especially challenging under logistically constrained conditions such as tropical forests in developing countries.

A remote sensing approach is essential and such an application has provided key information for the comprehension of ecological system dynamics. For example, it has been used to study the responses of both the Amazon forest canopy to drought [13], and the intra-annual and inter-annual variations of the enhanced vegetation index (EVI) in Brazilian tropical forests [14]. Remote sensing has also been used to predict and map forest structure and density in southeastern Madagascar [15], and to examine the relationship between Mexican tropical vegetation and rainfall [16]. Moreover, a number of change detection algorithms for use with satellite imagery have been tested and applied [5].

Another approach is to use the differential surface heat flux response of bare versus vegetated land. This appears to offer a means for the investigation of the status of land surface cover, and a number of studies have investigated the relationship between temperature and vegetation cover [17]-[24]. It is widely acknowledged that land surface temperature (LST) is determined by different land cover characteristics. Yue, Xu, Tan, et al. [25] suggested that dense vegetation cover might cause relatively higher evapotranspiration from the land surface to the atmosphere. This evapotranspiration could reduce land surface heat in comparison with open or bare land. In contrast, if vegetation loss occurred (i.e., large-scale forest clearance), this would be likely to increase LST.

Research has proven that using LST and the EVI can be useful for distinguishing differences in land cover [1] [7] [26] [27]. Using LST and EVI time-series data from the Moderate Resolution Imaging Spectroradiometer (MODIS) offers the potential to detect changes in land covers, such as with the disturbance index (DI). The DI was developed by Mildrexler, Zhao, Heinsch, et al. [3] and Mildrexler, Zhao and Running [27] to monitor global vegetation changes, and the approach was tested and shown to work well in forests of the United States and Canada [7].

In theory, the DI uses a combination of the EVI and LST indices for detecting and monitoring the changes in land covers on global scales. However, there are known problems related to cloud cover, atmospheric water column content, and aerosol haze when employing the EVI in tropical regions [28] [29]. There has been no implementation or evaluation of the DI model in tropical regions [2] [27] [30] and there is little known about whether EVI and LST could be useful in detecting changes in land covers in this region. Therefore, the aim of this research was to demonstrate and evaluate the DI for detecting spatial change in land covers in the south of Lao People's Democratic Republic (PDR). We used MODIS EVI and LST data time series from 2006-2012 in the DI model, and used high resolution Google Earth ${ }^{\mathrm{TM}}$ images (2006 and 2012) to evaluate the performance of the DI.

\section{Methods}

\subsection{Study Area}

The study area is located in Champasack Province in the south of Lao PDR. This area was selected because of its reasonably high geographic uniformity and large areas of homogeneous land cover. Additionally, this area was selected because of the availability of images from Google Earth ${ }^{\mathrm{TM}}$ for the evaluation of the success of the DI model.

The study site shown in Figure 1 covers an area of $15,415 \mathrm{~km}^{2}\left(13^{\circ} 55^{\prime} 00^{\prime \prime} \mathrm{N}-15^{\circ} 22^{\prime} 00^{\prime \prime} \mathrm{N}, 105^{\circ} 13^{\prime} 00^{\prime \prime} \mathrm{E}-\right.$ $106^{\circ} 55^{\prime} 00^{\prime E}$ ). Approximately 58\% of Champasack Province is covered by native forests, which comprise a range of natural ecosystems such as dry, mixed evergreen, deciduous tropical forests, savanna, and semi-dry evergreen forests. Two of the largest national protected areas of Lao PDR are encompassed within the area: Xepian and Dong Houa Sao. Champasack is divided by the Mekong River. The majority of the terrain is relatively flat (74\%), while $26 \%$ of the area has higher elevations. Overall, the elevation ranges from $75-1284 \mathrm{~m}$, but the majority of land is around $75-120 \mathrm{~m}$ above sea level. There are two distinct seasons: rainy (May-October) and dry (November-April). During the rainy season, it is often windy; humidity is high, and most of the annual average rainfall of 2279 mm occurs. During the dry season, conditions are mostly sunny with average temperatures 


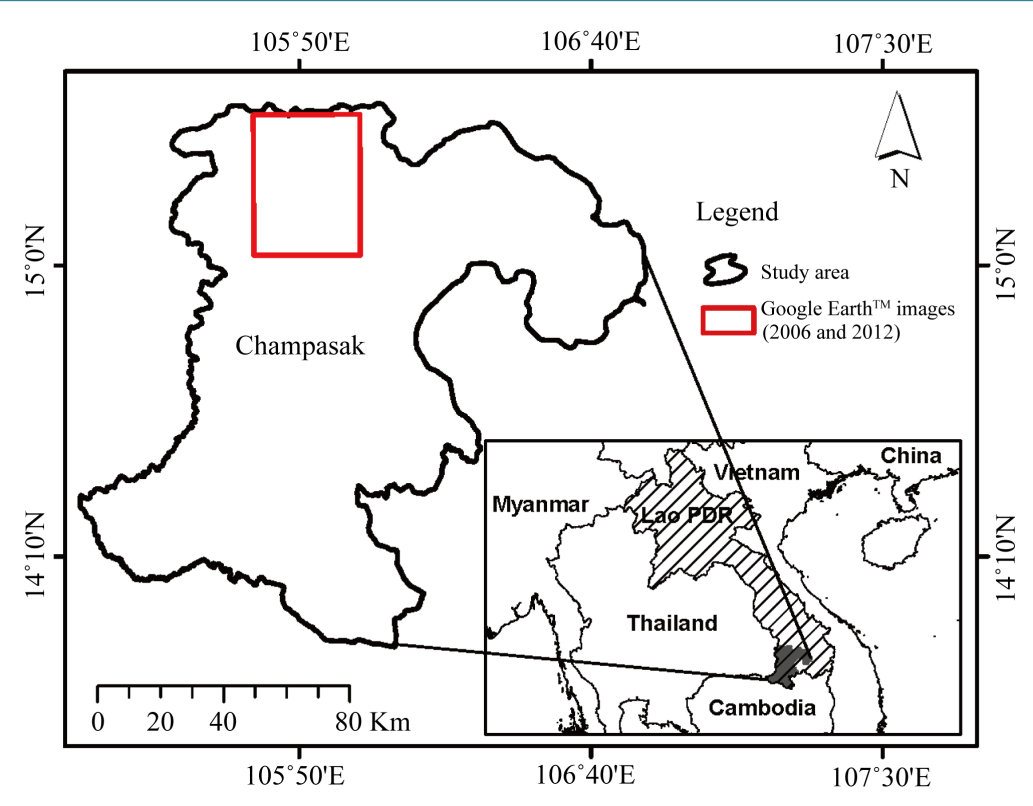

Figure 1. Location of the study area in Champasack Province, southern Lao PDR.

of $21^{\circ} \mathrm{C}-35^{\circ} \mathrm{C}$ and little rainfall. The volcanic soil of the area provides suitable growing conditions for coffee trees.

\subsection{Method Overview}

Our research comprised three major steps: 1) data collection and image preprocessing, 2) application of the DI algorithm to detect vegetation cover change, and 3) evaluation of the results of the DI (Figure 2).

\subsubsection{Data Collection and Image Preprocessing}

We used the MODIS Terra vegetation index products (MOD13A2 and MOD11A2, tile h28v07) from Collection 5 with 1-km spatial resolution. MODIS data were retrieved from the Earth Resource Observation and Science Center (EROS), National Aeronautics and Space Administration (NASA) using the ModisDownload R script. The time series spans the period from January 2006 to December 2012 with 16-day intervals (23 time steps) for MOD13A2 and 8-day intervals (46 time steps) for MOD11A2. The EVI is a vegetation index using the red, blue and NIR reflectance, as shown in Equation (1):

$$
\mathrm{EVI}=2.5 x \frac{(\mathrm{NIR}-\mathrm{red})}{(1+\mathrm{NIR}+6 x \text { red }-7.5 x \text { blue })}
$$

The EVI was selected because the algorithm is improved both for sensitivity to regions of high biomass and for vegetation monitoring through a de-coupling of the canopy background signal and a reduction in atmospheric influences [7] [31]-[34].

In this research, image preprocessing selected only good quality pixels of the MODIS data to avoid bias. Thus, we extracted pairs of MODIS EVI and LST time series data and their quality assurance layers (QA). Then, bad quality pixels were masked by the QA or via enclosed Pixel Reliability datasets (value $=0$; good data, use with confidence). Those time-series datasets were subsetted and reprojected to WGS84, UTM zone 48N, using the MODIS reprojection tool (version 4.01).

\subsubsection{Applying the DI Algorithm}

The DI algorithm was tested for detecting changes in vegetation cover for the entire Champasack Province using the MODIS EVI and LST data time series from 2006-2012. The DI created by Mildrexler, Zhao, Heinsch, et al. [3] and refined by Mildrexler, Zhao and Running [27] is calculated as: 


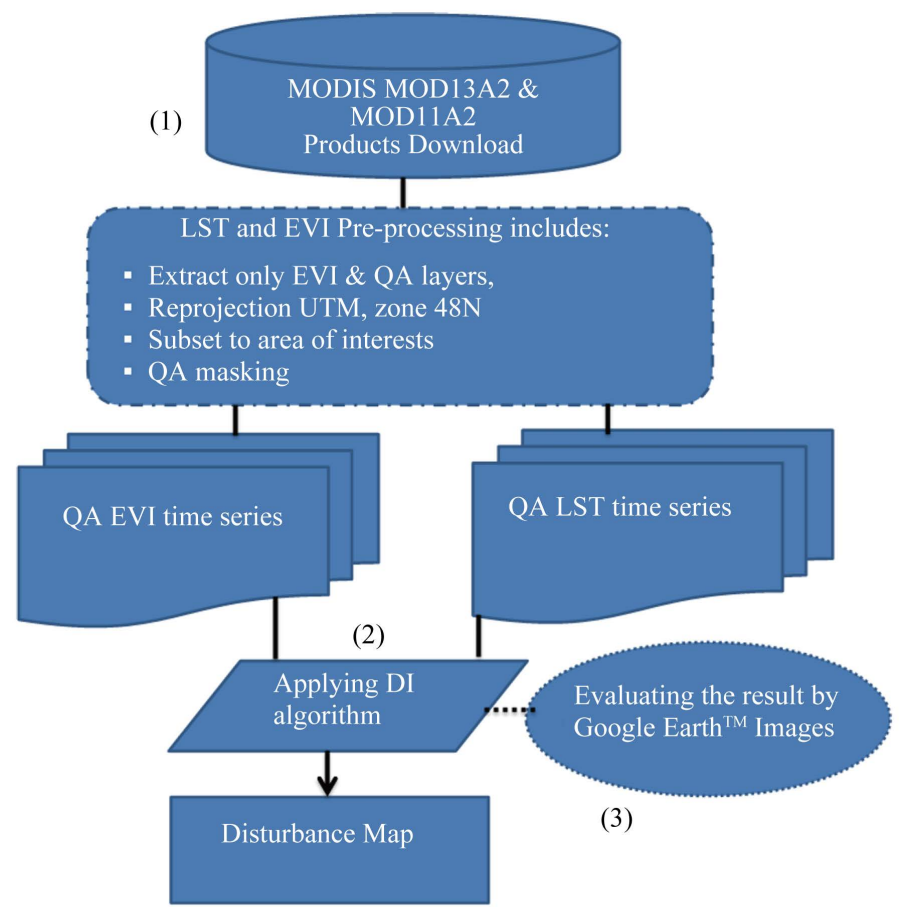

Figure 2. Research steps.

$$
\mathrm{DI}_{i}=\frac{\left(\frac{L S T_{\text {imax }}}{E V I_{\text {imax }}}\right)}{\sum_{i-1}\left(\frac{L S T_{\max }}{E V I_{\text {max }}}\right)}
$$

where $D I_{i}$ is the disturbance index value for year $i ; L S T_{i \max }$ is the annual maximum eight-day composite $L S T$ for year $i$; $E V I_{\text {max }}$ is the annual maximum 16-day $E V I$ for year $i ; L S T_{\max }$ is the multiyear mean $L S T$ (maximum) up to, but not including the analysis year ( $i-1$ ); and $E V I_{\max }$ is the multiyear mean of $E V I$ (maximum) up to, but not including the analysis year $(i-1)$.

The DI was designed for detecting changes in land covers on a pixel-by-pixel basis [3] [27]. The output from our pixel calculations is unitless. We used the same standard of threshold setting as in previous research [2] [3] [7] [27], and values of DI were set as the mean \pm 1 standard deviation (SD). An output map of the DI was classified into three classes: increased, stable, and decreased vegetation. Larger the mean (+) 1SD was assigned to decreased vegetation, whereas less than the mean $(-)$ 1SD, signified increased vegetation. The rest was designated as stable vegetation. Normally, DI values of natural variability with no substantial change in land covers or stable vegetation fall within a narrow range around 1.0.

\subsubsection{Evaluating the Results of the DI Model}

The final research step was to evaluate the effectiveness of the DI in detecting spatial changes in vegetation cover within the study area. We evaluated the output map of the DI by Google Earth ${ }^{\mathrm{TM}}$ Images in 2006 and 2012.

Table 1 represents our interpretation of the change in land covers between 2006 and 2012, from the Google Earth $^{\mathrm{TM}}$ images. Firstly, we identified and classified land covers from the Google Earth ${ }^{\mathrm{TM}}$ imagery into four dominant land cover types: native forest, plantation, mixed wooded/cleared area and agriculture. Secondly, we digitized these land covers as polygons in order to calculate their changes between 2006 and 2012 using ArcGIS10.2.1 software. This vegetation change map was assigned into the same three categories corresponding to those used in the DI application: 1) Stable vegetation is an area that appears to exhibit little or no change between the images; 2) Increased vegetation means an area that shows an increase in vegetation cover such as the 
Table 1. Matrix of interpreted land cover transitions.

\begin{tabular}{ccccc}
\hline Transition of land cover from/to & Native forest & Plantation & Mixed wooded/cleared & Agriculture \\
\hline Native forest & S & DV & DV & DV \\
Plantation & NA & S & NA & S \\
Mixed wooded/cleared & IV & IV & IV & DV \\
Agriculture & NA & IV & S
\end{tabular}

Note: IV = increased vegetation, $\mathrm{S}=$ stable vegetation, DV = decreased vegetation, $\mathrm{NA}=$ not found in our case.

transition from mixed wooded/cleared areas or bare land to plantation; and 3) Decreased vegetation indicates the clearance or loss of vegetation, i.e., the transition of native forest to mixed wooded/cleared areas or agricultural land. This information was used as evaluation data for the DI.

Thirdly, the output map of the DI and the evaluation data from the Google Earth ${ }^{\mathrm{TM}}$ were overlaid (Figure 3). This comparison was to evaluate whether the DI can detect detailed changes in land covers. We used 1207 random samples within the total assessment area of approximately $2500 \mathrm{~km}^{2}$. This area was determined by the availability of high resolution Google Earth ${ }^{\mathrm{TM}}$ images in two dates 2006 and 2012 over the same location (Figure 4). The unit of comparison was based on a pixel of MODIS $(1 \times 1 \mathrm{~km})$. Finally, summary of the Disturbance Index accuracy assessment was provided.

\section{Results and Discussion}

\subsection{Accuracy Assessment}

The DI was implemented to detect spatial changes in land covers within our study area during the seven-year period from 2006-2012. The results of its accuracy assessment are presented in Table 2, and an example of a comparison of the results with the Google Earth ${ }^{\mathrm{TM}}$ imagery is shown in Figure 3. The overall accuracy of the DI output is $82 \%$ and its Kappa statistic is 0.59 , although the user's and producer's accuracies for individual classes differ. The producer's and user's accuracies for the class of stable vegetation (areas of little change or minor disturbance; $90.37 \%$ and $89.95 \%$, respectively) are higher than for the other vegetation change classes. Increased vegetation suggested by the DI shows lower percentages of both producer's (66.67\%) and user's accuracy (65.72\%), and areas of decreased vegetation cover have the lowest accuracy (producer's $42.42 \%$ and user's $48.28 \%$ ). The DI appears to detect changes in vegetation cover within the study area with high overall accuracy, but lower accuracy for areas in which the vegetation has decreased.

\subsection{Visualizing Changes in Google Earth ${ }^{\mathrm{TM}}$}

Figure 3 shows the spatial changes in land covers detected by the DI model and its comparison of changes with high-resolution images from Google Earth ${ }^{\mathrm{TM}}$ in the same period (2006 and 2012). The model appears to detect and locate patterns of change in land covers, especially highlighting areas where vegetation has increased or remained unchanged. Increased vegetation is found mostly in plantation areas, but stable vegetation areas are located in agricultural regions and some parts of the native forest within the protected areas (Figure 4). The DI can indicate areas of vegetation decrease; however, some of these areas were not detected well, including native forest clearances. The interpretation of the Google Earth ${ }^{\mathrm{TM}}$ indicates that most forest clearance has occurred in relatively tiny areas, due to shifting cultivation practices and small-sized agriculture. Some of these small scattered areas of forest clearances went undetected by the model. This approach tends to capture large spatial changes in land covers, preferably $>1 \mathrm{~km}^{2}$. For example, continuous extended areas showing an increase in vegetation cover were well detected, such as rubber plantations.

Table 3 indicates that about 2.5\% of the total area of vegetation cover was lost from 2006 to 2012, while approximately $6.65 \%$ of the entire provincial land shows an increase in vegetation cover. This increase was the result of the expansion of rubber plantations within this area. A large proportion of the vegetation decrease was found in native forests, near the protected areas, and in the mixed wooded/cleared area in the north of Champasak Province. 


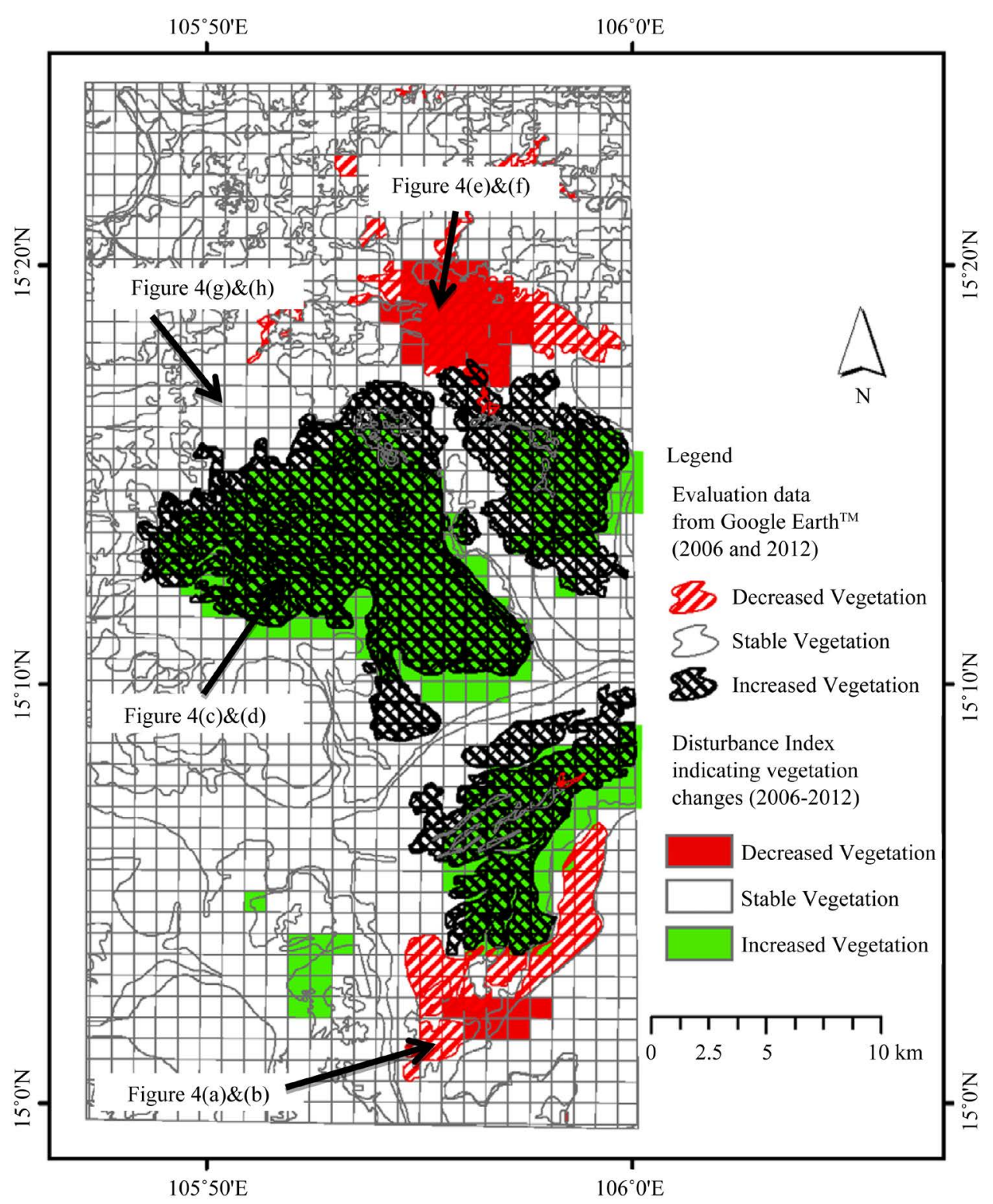

Figure 3. Comparison of changes in land covers over the seven-year period (2006-2012) detected by the Disturbance Index with the evaluation data from Google Earth ${ }^{\mathrm{TM}}$ images. Red pixels and red striped lines indicate decreased vegetation, green pixels and green striped lines indicate vegetation increase, and white pixels and white polygons show stable vegetation.

\section{Conclusion}

In this research, we demonstrated and evaluated the global disturbance index, which used a combination of EVI and LST indices. We used MODIS EVI and LST time series data (from 2006-2012) to test whether this approach was useful for detecting land cover change in Lao tropical forests. An evaluation of the performance of the DI was performed by comparing its results with corresponding high-resolution images from Google Earth ${ }^{\mathrm{TM}}$. The key findings were that the DI was capable of detecting vegetation changes within our study area during the seven-year period with high overall accuracy (82\%); however, it showed low accuracy in detecting decreases in vegetation (about 42\%). Even though this model is straight forward and can be used for rapid assessment of land cover changes in the tropics, it may not be useful for assessing vegetation loss when high accuracy is required. Further investigation is required into the atmospheric and climate effects on MODIS LST and EVI in the application of the model. 


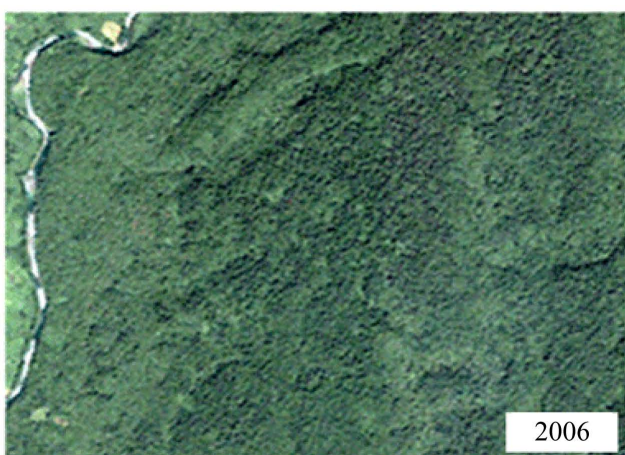

(a)

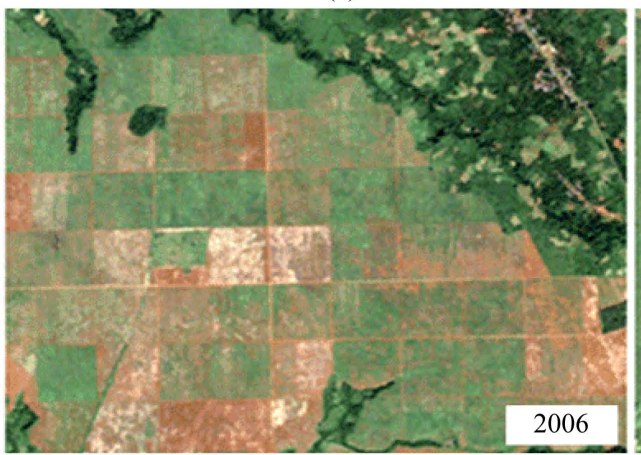

(c)

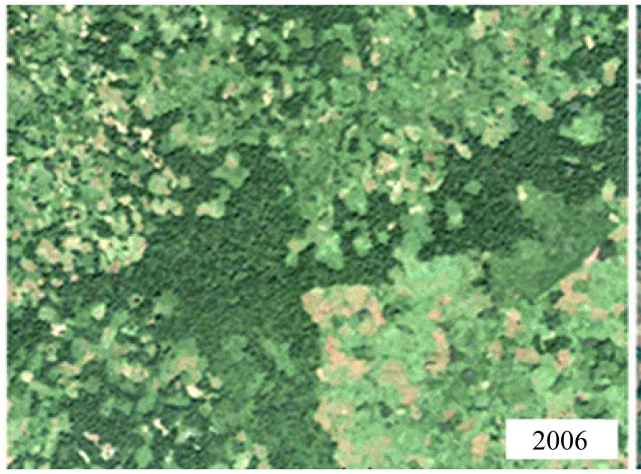

(e)

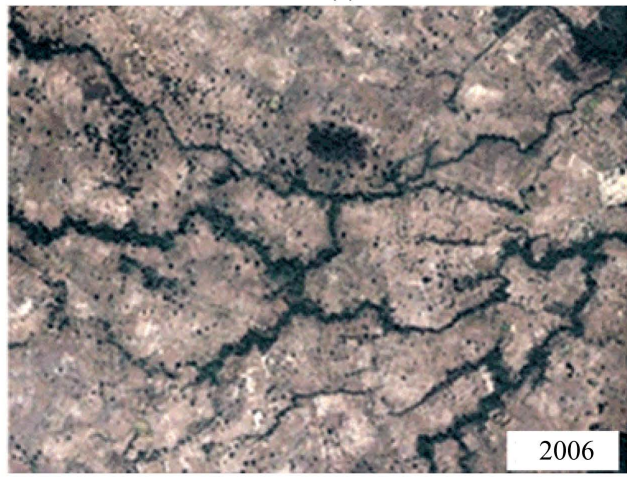

(g)

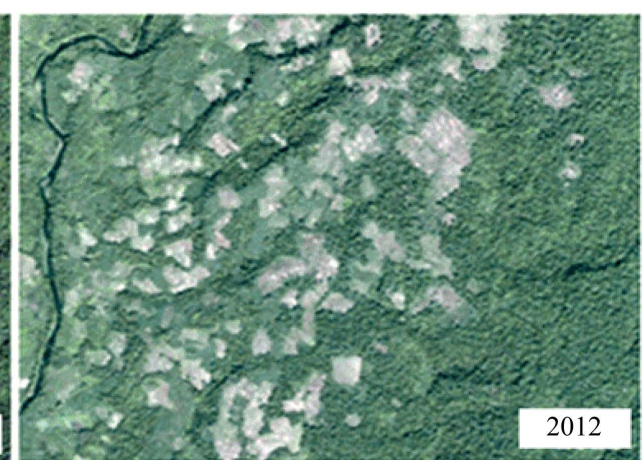

(b)

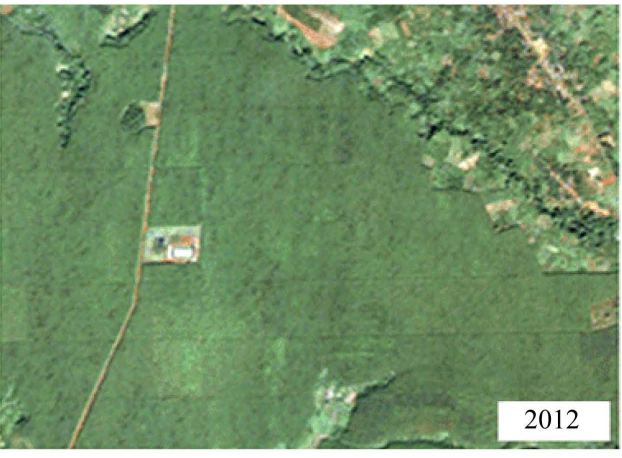

(d)

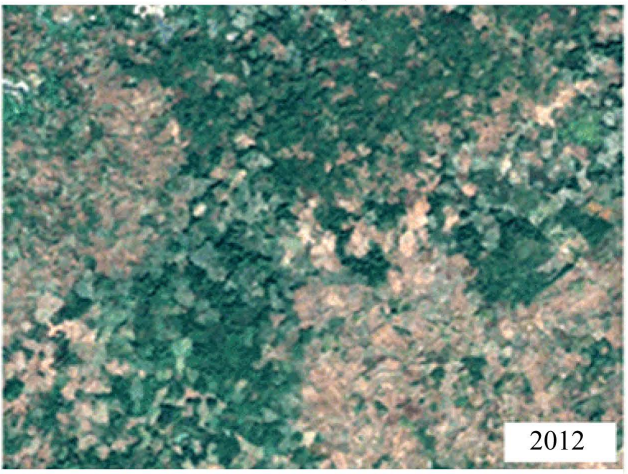

(f)

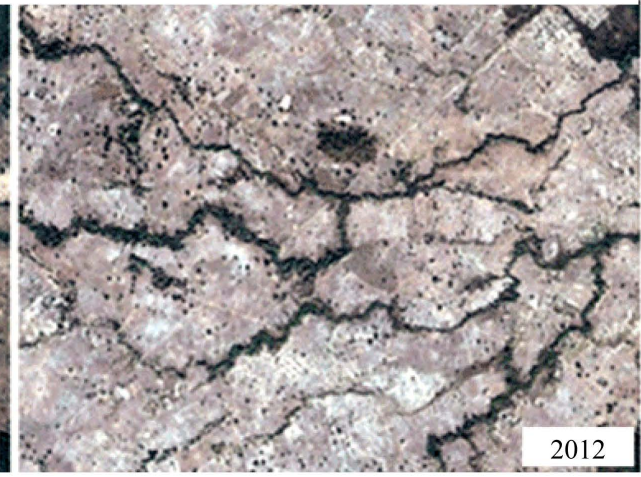

(h)

Figure 4. Example of the Google Earth ${ }^{\mathrm{TM}}$ images showing land cover changes between 2006 and 2012, from locations in Figure 3. (a) undisturbed forest in 2006, (b) disturbed native forest in 2012; (c) land clearance in 2006, (d) rubber plantations in 2012, (e) mixed wood and cleared areas in 2006, (f) reduced areas of wood and increased clearances in 2012, (g) \& (h) unchanged agricultural areas in 2006 and 2012, respectively. 
Table 2. Summary of the disturbance index accuracy assessment.

\begin{tabular}{|c|c|c|c|c|c|}
\hline \multirow{2}{*}{ Google Earth ${ }^{\mathrm{TM}}$ (2006 and 2012) } & \multicolumn{3}{|c|}{ Disturbance Index } & \multirow{2}{*}{ Total } & \multirow{2}{*}{$\begin{array}{c}\text { Producer’s Accuracy } \\
\text { (\%) }\end{array}$} \\
\hline & IV & $\mathrm{S}$ & DV & & \\
\hline IV & 186 & 87 & 6 & 279 & 66.67 \\
\hline S & 59 & 779 & 24 & 862 & 90.37 \\
\hline DV & 38 & 0 & 28 & 66 & 42.42 \\
\hline Total & 283 & 866 & 58 & 1207 & \\
\hline User’s Accuracy (\%) & 65.72 & 89.95 & 48.28 & & $82 \%$ \\
\hline
\end{tabular}

$\mathrm{IV}=$ increased vegetation, $\mathrm{S}=$ stable vegetation, $\mathrm{DV}=$ decreased vegetation.

Table 3. Estimated area of vegetation cover changes from 2006-2012.

\begin{tabular}{cccc}
\hline \multirow{2}{*}{ Vegetation Cover Changes } & \multicolumn{2}{c}{ Years 2006-2012 } & \multirow{2}{*}{ Total Area $\left(\mathrm{km}^{2}\right)$} \\
\cline { 2 - 3 } & Area $\left(\mathrm{km}^{2}\right)$ & Percentage $(\%)^{*}$ & 15,415 \\
\hline Decreased Vegetation & 386 & $2.50 \%$ & $6.65 \%$ \\
Increased Vegetation & 1026 &
\end{tabular}

*The percentage of vegetation cover change was calculated from numbers of pixels $\left(1 \mathrm{~km}^{2}\right)$ indicating change, divided by the total area $\left(15,415 \mathrm{~km}{ }^{2}\right)$, and multiplied by 100 .

\section{Acknowledgements}

This study was supported by the Australian Agency for International Development (AusAID). Special acknowledgment is given to the National Aeronautics and Space Administration (NASA) and Google Earth ${ }^{\mathrm{TM}}$ for providing freely available images that were used for this research.

\section{References}

[1] Chernetskiy, M., Pasko, I., Shevyrnogov, A., et al. (2011) A Study of Forest Vegetation Dynamics in the South of the Krasnoyarskii Krai in Spring. Advances in Space Research, 48, 819-825. http://dx.doi.org/10.1016/j.asr.2011.04.032

[2] Coops, N.C., Duro, D.C., Wulder, M.A., et al. (2007) Estimating afternoon MODIS Land Surface Temperatures (LST) Based on Morning MODIS Overpass, Location and Elevation Information. International Journal of Remote Sensing, 28, 2391-2396. http://dx.doi.org/10.1080/01431160701294653

[3] Mildrexler, D.J., Zhao, M., Heinsch, F.A., et al. (2007) A New Satellite-Based Methodology for Continental-Scale Disturbance Detection. Ecological Applications, 17, 235-250. http://dx.doi.org/10.1890/1051-0761(2007)017[0235:ANSMFC]2.0.CO;2

[4] Klein, I., Gessner, U. and Kuenzer, C. (2012) Regional Land Cover Mapping and Change Detection in Central Asia Using MODIS Time-Series. Applied Geography, 35, 219-234. http://dx.doi.org/10.1016/j.apgeog.2012.06.016

[5] Lu, D., Mausel, P., Brondízio, E., et al. (2004) Change Detection Techniques. International Journal of Remote Sensing, 25, 2365-2401. http://dx.doi.org/10.1080/0143116031000139863

[6] Xin, Q.C., Olofsson, P., Zhu, Z., et al. (2013) Toward near Real-Time Monitoring of Forest Disturbance by Fusion of MODIS and Landsat Data. Remote Sensing of Environment, 135, 234-247. http://dx.doi.org/10.1016/j.rse.2013.04.002

[7] Coops, N.C., Wulder, M.A. and Iwanicka, D. (2009) Large Area Monitoring with a MODIS-Based Disturbance Index (DI) Sensitive to Annual and Seasonal Variations. Remote Sensing of Environment, 113, 1250-1261. http://dx.doi.org/10.1016/j.rse.2009.02.015

[8] Ghazoul, J. (2013) Deforestation and Land Clearing. In: Levin, S.A., Ed., Encyclopedia of Biodiversity, 2nd Edition, Academic Press, Waltham, 447-456.

[9] Bradshaw, C.J. (2012) Little Left to Lose: Deforestation and Forest Degradation in Australia since European Colonization. Journal of Plant Ecology, 5, 109-120. http://dx.doi.org/10.1093/jpe/rtr038

[10] Hilbert, D.W., Ostendorf, B. and Hopkins, M.S. (2001) Sensitivity of Tropical Forests to Climate Change in the Humid Tropics of North Queensland. Austral Ecology, 26, 590-603. http://dx.doi.org/10.1046/j.1442-9993.2001.01137.x

[11] Ostendorf, B., Hilbert, D.W. and Hopkins, M.S. (2001) The Effect of Climate Change on Tropical Rainforest Vegeta- 
tion Pattern. Ecological Modelling, 145, 211-224. http://dx.doi.org/10.1016/S0304-3800(01)00392-1

[12] Ostendorf, B. (2011) Overview: Spatial Information and Indicators for Sustainable Management of Natural Resources. Ecological Indicators, 11, 97-102. http://dx.doi.org/10.1016/j.ecolind.2010.10.003

[13] Asner, G.P. and Alencar, A. (2010) Drought Impacts on the Amazon Forest: The Remote Sensing Perspective. New Phytologist, 187, 569-578. http://dx.doi.org/10.1111/j.1469-8137.2010.03310.X

[14] Moura, Y.M., Galvão, L.S., dos Santos, J.R., Roberts, D.A. and Breunig, F.M. (2012) Use of MISR/Terra Data to Study Intra- and Inter-Annual EVI Variations in the Dry Season of Tropical Forest. Remote Sensing of Environment, 127, 260-270. http://dx.doi.org/10.1016/j.rse.2012.09.013

[15] Ingram, J.C., Dawson, T.P. and Whittaker, R.J. (2005) Mapping Tropical Forest Structure in Southeastern Madagascar Using Remote Sensing and Artificial Neural Networks. Remote Sensing of Environment, 94, 491-507. http://dx.doi.org/10.1016/j.rse.2004.12.001

[16] Miranda-Aragón, L., Treviño-Garza, E.J., Jiménez-Pérez, J., Aguirre-Calderón, O.A., González-Tagle, M.A., PompaGarcía, M., et al. (2012) NDVI-Rainfall Relationship Using Hyper-Temporal Satellite Data in a Portion of North Central Mexico (2000-2010). African Journal of Agricultural Research, 7, 1023-1033.

[17] Zhang, X.X., Wu, P.F. and Chen, B. (2010) Relationship between Vegetation Greenness and Urban Heat Island Effect in Beijing City of China. Procedia Environmental Sciences, 2, 1438-1450. http://dx.doi.org/10.1016/j.proenv.2010.10.157

[18] Raynolds, M.K., Comiso, J.C., Walker, D.A. and Verbyla, D. (2008) Relationship between Satellite-Derived Land Surface Temperatures, Arctic Vegetation Types, and NDVI. Remote Sensing of Environment, 112, 1884-1894. http://dx.doi.org/10.1016/j.rse.2007.09.008

[19] Weng, Q., Lu, D. and Schubring, J. (2004) Estimation of Land Surface Temperature-Vegetation Abundance Relationship for Urban Heat Island Studies. Remote Sensing of Environment, 89, 467-483. http://dx.doi.org/10.1016/j.rse.2003.11.005

[20] Xiao, H. and Weng, Q. (2007) The Impact of Land Use and Land Cover Changes on Land Surface Temperature in a Karst Area of China. Journal of Environmental Management, 85, 245-257. http://dx.doi.org/10.1016/j.jenvman.2006.07.016

[21] Weng, Q. and Lu, D. (2008) A Sub-Pixel Analysis of Urbanization Effect on Land Surface Temperature and Its Interplay with Impervious Surface and Vegetation Coverage in Indianapolis, United States. International Journal of Applied Earth Observation and Geoinformation, 10, 68-83. http://dx.doi.org/10.1016/j.jag.2007.05.002

[22] Jiang, J. and Tian, G. (2010) Analysis of the Impact of Land Use/Land Cover Change on Land Surface Temperature with Remote Sensing. Procedia Environmental Sciences, 2, 571-575. http://dx.doi.org/10.1016/j.proenv.2010.10.062

[23] Zhou, W., Huang, G. and Cadenasso, M.L. (2011) Does Spatial Configuration Matter? Understanding the Effects of Land Cover Pattern on Land Surface Temperature in Urban Landscapes. Landscape and Urban Planning, 102, 54-63. http://dx.doi.org/10.1016/j.landurbplan.2011.03.009

[24] Herdianto, R., Paik, K., Coles, N.A. and Smettem, K. (2013) Transitional Responses of Vegetation Activities to Temperature Variations: Insights Obtained from a Forested Catchment in Korea. Journal of Hydrology, 484, 86-95. http://dx.doi.org/10.1016/j.jhydrol.2013.01.011

[25] Yue, W., Xu, J., Tan, W. and Xu, L. (2007) The Relationship between Land Surface Temperature and NDVI with Remote Sensing: Application to Shanghai Landsat 7 ETM+ Data. International Journal of Remote Sensing, 28, 32053226. http://dx.doi.org/10.1080/01431160500306906

[26] Webb, E.L., Jachowski, N.R.A., Phelps, J., Friess, D.A., Thand, M.M. and Zieglerb, A.D. (2014) Deforestation in the Ayeyarwady Delta and the Conservation Implications of an Internationally-Engaged Myanmar. Global Environmental Change, 24, 321-333. http://dx.doi.org/10.1016/j.gloenvcha.2013.10.007

[27] Mildrexler, D.J., Zhao, M. and Running, S.W. (2009) Testing a MODIS Global Disturbance Index across North America. Remote Sensing of Environment, 113, 2103-2117. http://dx.doi.org/10.1016/j.rse.2009.05.016

[28] Grogan, K. and Fensholt, R. (2013) Exploring Patterns and Effects of Aerosol Quantity Flag Anomalies in MODIS Surface Reflectance Products in the Tropics. Remote Sensing, 5, 3495-3515. http://dx.doi.org/10.3390/rs5073495

[29] Samanta, A., Ganguly, S., Vermote, E., Nemani, R.R. and Myneni, R.B. (2012) Interpretation of Variations in MODISMeasured Greenness Levels of Amazon Forests during 2000 to 2009. Environmental Research Letters, 7, 1-12. http://dx.doi.org/10.1088/1748-9326/7/2/024018

[30] Mildrexler, D.J., Zhao, M. and Running, S.W. (2011) A Global Comparison between Station Air Temperatures and MODIS Land Surface Temperatures Reveals the Cooling Role of Forests. Journal of Geophysical Research, 116, 1-15. http://dx.doi.org/10.1029/2010JG001486

[31] Huete, A.R., Didan, K., Shimabukuro, Y.E., Ratana, P., Saleska, S.R., Hutyra, L.R., et al. (2006) Amazon Rainforests 
Green-Up with Sunlight in Dry Season. Geophysical Research Letters, 33, 1-4. http://dx.doi.org/10.1029/2005GL025583

[32] Huete, A.R., Restrepo-Coupe, N., Ratana, P., Didan, K., Saleska, S.R., Ichii, K., et al. (2008) Multiple Site Tower Flux and Remote Sensing Comparisons of Tropical Forest Dynamics in Monsoon Asia. Agricultural and Forest Meteorology, 148, 748-760. http://dx.doi.org/10.1016/j.agrformet.2008.01.012

[33] Senf, C., Pflugmacher, D., van der Linden, S. and Hostert, P. (2013) Mapping Rubber Plantations and Natural Forests in Xishuangbanna (Southwest China) Using Multi-Spectral Phenological Metrics from MODIS Time Series. Remote Sensing, 5, 2795-2812. http://dx.doi.org/10.3390/rs5062795

[34] Zhang, X., Friedl, M.A., Schaaf, C.B. and Strahler, A.H. (2005) Monitoring the Response of Vegetation Phenology to Precipitation in Africa by Coupling MODIS and TRMM Instruments. Journal of Geophysical Research, 110, 1-14. 